\title{
The altered transcriptome of pediatric myelodysplastic syndrome revealed by RNA sequencing
}

\author{
Lorena Zubovic ${ }^{1 *}$, Silvano Piazza ${ }^{2}$,Toma Tebaldi ${ }^{3}$, Luca Cozzuto ${ }^{4}$, Giuliana Palazzo ${ }^{1}$, Viktoryia Sidarovich ${ }^{5}$, \\ Veronica De Sanctis ${ }^{6}$, Roberto Bertorelli ${ }^{6}$, Tim Lammens ${ }^{7}$, Mattias Hofmans ${ }^{7}$, Barbara De Moerloose ${ }^{7}$, \\ Julia Ponomarenko ${ }^{4,8}$, Martina Pigazzi $^{9}$, Riccardo Masetti ${ }^{10}$, Cristina Mecucci ${ }^{11}$, Giuseppe Basso ${ }^{12,13}$ \\ and Paolo Macchi ${ }^{i^{*}}$ (1)
}

\begin{abstract}
Pediatric myelodysplastic syndrome (PMDS) is a very rare and still poorly characterized disorder. In this work, we identified novel potential targets of PMDS by determining genes with aberrant expression, which can be correlated with PMDS pathogenesis. We identified 291 differentially expressed genes (DEGs) in PMDS patients, comprising genes involved in the regulation of apoptosis and the cell cycle, ribosome biogenesis, inflammation and adaptive immunity. Ten selected DEGs were then validated, confirming the sequencing data. These DEGs will potentially represent new molecular biomarkers and therapeutic targets for PMDS.
\end{abstract}

Keywords: Differentially expressed genes, Transcriptome, Pediatrics, Myelodysplastic syndrome

\section{To the Editor}

MDSs are a heterogeneous group of clonal hematopoietic neoplasms. Although recent studies have shown that MDS and AML patients had different gene mutation patterns [1-4], the molecular underpinnings remain unknown [5-10]. To identify DEGs related to the PMDS, we performed RNA-seq in 4 patients with primary PMDS and in 2 control pediatric samples (Additional file 1: Figures S1A-B). Because of the limited number of samples and to limit the false positives, we used two independent bioinformatics pipelines, STAR + DESeq2 and SALMON + edgeR, and considered only genes differentially expressed in both pipelines. Hierarchical clustering showed that PMDS patients and controls

\footnotetext{
*Correspondence: Iorena.zubovic@unitn.it; paolo.macchi@unitn.it 1 Laboratory of Molecular and Cellular Neurobiology, Department of Cellular, Computational and Integrative Biology - CIBIO, University of Trento, Trento, Italy

Full list of author information is available at the end of the article
}

clustered in two distinct groups (Fig. 1a). In total, 651 DEGs were identified by STAR + DESeq 2 and 616 DEGs by SALMON+edgeR (Fig. 1B; Additional file 1: Figures S1C-D). 291 DEGs were identified by both pipelines among which 136 genes were upregulated and 155 downregulated in patients (Additional file 1: Table 1). As a further validation, we used the LPEseq method. The concordance of the genes in the ranks of the differential gene lists was remarkably high (Additional file 1: Figures S1EG). We then used GSEA to identify altered pathways from the Reactome database (Web reference 1) (Fig. 1c). The Enrichr enrichment analysis tool revealed that DEGs in PMDS are mainly related to pathways associated with the cell abnormal activity, immune and inflammatory systems and erythropoiesis (Additional file 1: Figure S2A).

Further, we compared our data with the transcriptomic profiles from TCGA database. Interestingly, we found a clear distinction of PMDS from all other types of tumors (Fig. 2a; Additional file 1: Figure S2B). Moreover, the DEGs profile was able to divide tumors original author(s) and the source, provide a link to the Creative Commons licence, and indicate if changes were made. The images or other third party material in this article are included in the article's Creative Commons licence, unless indicated otherwise in a credit line to the material. If material is not included in the article's Creative Commons licence and your intended use is not permitted by statutory regulation or exceeds the permitted use, you will need to obtain permission directly from the copyright holder. To view a copy of this licence, visit http://creativecommons.org/licenses/by/4.0/. The Creative Commons Public Domain Dedication waiver (http://creativeco mmons.org/publicdomain/zero/1.0/) applies to the data made available in this article, unless otherwise stated in a credit line to the data. 


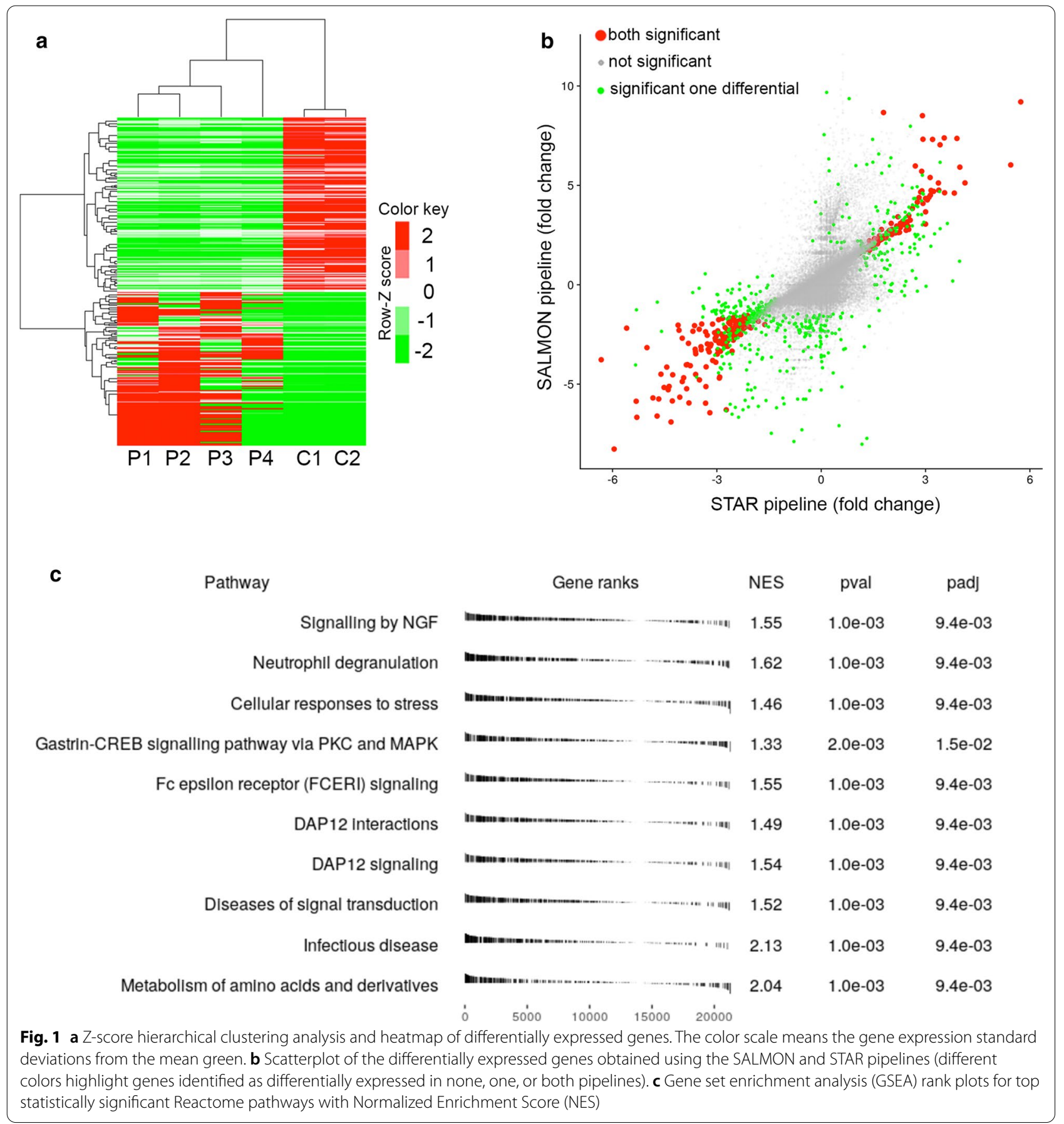

into three distinct groups (Additional file 1: Figure S3A). As for control samples, we integrated the transcriptomic data from the GTEx (Web reference 2) and observed a clear separation between blood related tissues and other normal tissues (Additional file 1: Figures S3B). Finally, we compared the DEGs gene list with the gene sets available in the Enrichr database specifically for "Diseases/Drugs" and "Cell types "categories
(Additional file 1: Tables 2-3). We confirmed that the DEGs identified in PMDS are significantly connected with blood tissues and blood disorders (Additional file 1: Figure S3C).

A comparison of our PMDS DEGs with multiple RNA-seq datasets from adult MDS samples revealed a statistically significant overlap (67 out of 136 DEGs). Nonetheless, 69 upregulated genes and almost all 
a

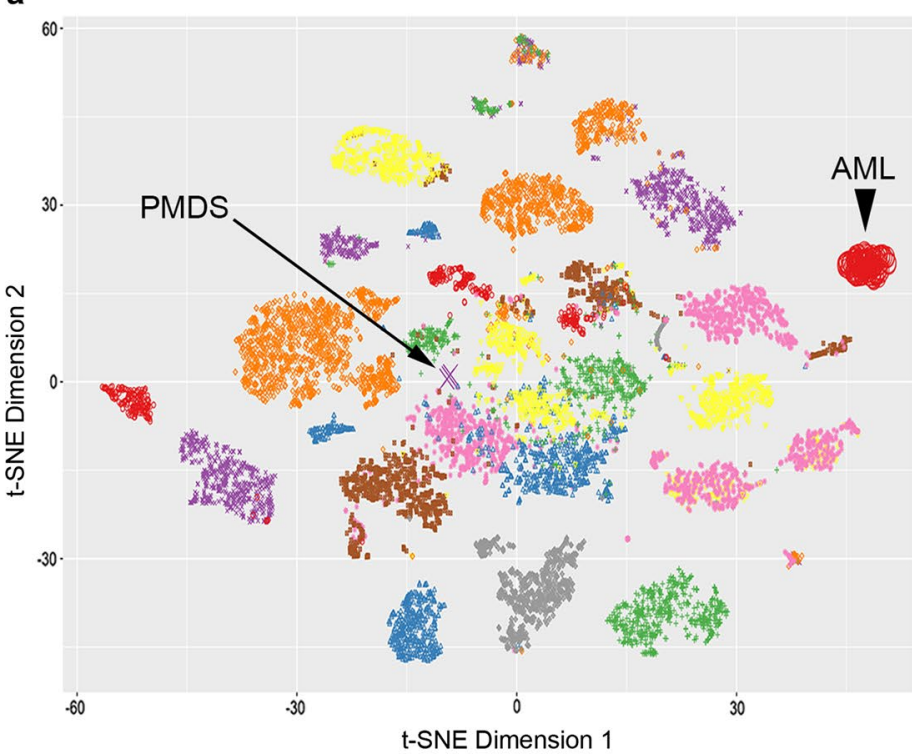

- Acute Myeloid Leukemia

$\triangle$ Adrenocortical Carcinoma

Bladder Urothelial Carcinoma

Brain Lower Grade Glioma

Breast Invasive Carcinoma

Cervical Squamous Cell Carcinoma and Endocervical Adenocarcinoma

a Cholangiocarcinoma

Colon Adenocarcinoma

- Esophageal Carcinoma

- Glioblastoma Multiforme

$\Delta$ Head and Neck Squamous Cell Carcinoma

Kidney Chromophobe

Kidney Renal Clear Cell Carcinoma

Kidney Renal Papillary Cell Carcinoma

Liver Hepatocellular Carcinoma

* Lung Adenocarcinoma

Lung Squamous Cell Carcinoma

- Lymphoid Neoplasm Diffuse Large 8-cell Lymphoma

Mesothelioma

$\triangle$ Ovarian Serous Cystadenocarcinoma

Pancreatic Adenocarcinoma

Pheochromocytoma and Paraganglioma

Prostate Adenocarcinoma

Rectum Adenocarcinoma

Sarcoma

Skin Cutaneous Melanoma

Stomach Adenocarcinoma

Testicular Germ Cell Tumors

Thymoma

Thyroid Carcinoma

PMDS

Uterine Carcinosarcoma

Uterine Corpus Endometrial Carcinoma

a Uveal Melanoma
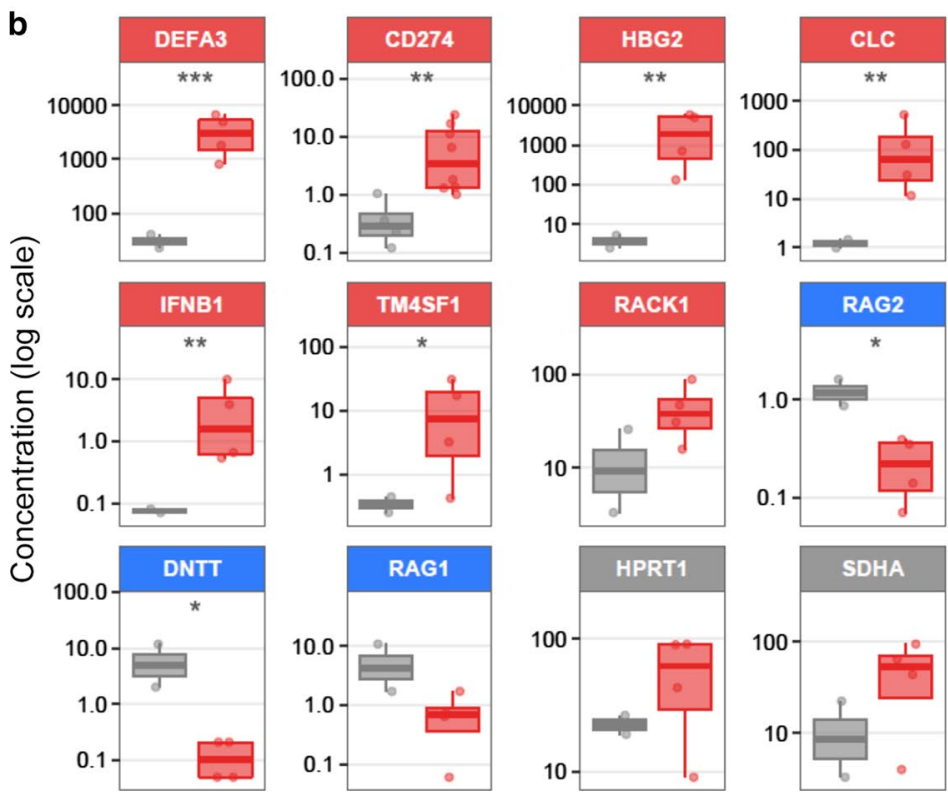

Ctrl

审 PMDS

Fig. 2 a T-distributed stochastic neighbor embedding (t-SNE) plot in the expression space of several cancer datasets, plotting the results of the two principal dimensions. The data were obtained from the GDC-PAN cancer data Portal. The PMDS samples do not cluster near other tumor types, AML in particular (black arrowhead), showing a distinct profile. b Boxplot: ddPCR analysis of twelve genes, comparing expression levels between controls and PMDS patients. For each gene, box-whisker plots of concentration values are shown. Genes are classified as upregulated (red), downregulated (blue) and reference (grey). Significant changes in cDNA concentration between control and patients are highlighted (one-tailed $t$ test, corrected for unequal variances ${ }^{*} p<0.05,{ }^{* *} p<0.01,{ }^{* * *} p<0.001$ ) 
downregulated genes were unique in PMDS (Additional file 1: Figure S4A-B; Additional file 1: Table 4).

Then, we validated the most statistically significant and biologically relevant DEGs either up- or downregulated. Analysis by ddPCR showed significant differences between patient and control samples (Fig. 2b). The log2 fold-change values for all 10 genes were highly correlated (Additional file 1: Figure S5). We also validated the DEGs in 6 new PMDS patients (Additional file 1: Figure S6). Additionally, we compared our data with 36 pediatric patients (3). The comparative data on 10 DEGs in PMDS and validation are shown in the Additional file 1: Figure S7.

In conclusion, we have identified 291 DEGs that correlate with the PMDS which might represent novel candidate genes for therapeutic intervention. Although a larger study cohort would be desirable, our data suggest that at the level of gene expression the PMDS is indeed a distinct disorder.

\section{Supplementary information}

Supplementary information accompanies this paper at https://doi. org/10.1186/s13045-020-00974-3.

Additional file 1. The altered transcriptome of pediatric myelodysplastic syndrome revealed by RNA sequencing.

\section{Abbreviations}

PMDS: Pediatric Myelodysplastic Syndrome; BM: Bone marrow; DEGs: : Differentially expressed genes; RNA-seq: RNA sequencing; MDSs: Myelodysplastic syndromes; AML: Acute myeloid leukemia; GSEA: Gene set enrichment analysis; GO: Gene ontology; HPO: Human phenotype ontologies; TCGA: The cancer genome atlas; GTEx: Genotype tissue expression; ddPCR: Digital droplet PCR.

\section{Acknowledgements}

We thank Prof. Juan Valcárcel Juárez, Dr. Giovanni Roti and Dr. Boshra Khalaf for their critical comments on the manuscript. We thank Dr. Jeffery M. Klco for sharing with us the RNA sequencing data to perform an integrative analysis with our results. We thank the Next Generation Sequencing (NGS) facility (Department CIBIO) for the RNA-seq analysis and the High Throughput Screening (HTS) facility (Department CIBIO) for the help with the ddPCR analysis. This work is dedicated to the memory of Dr. Luca Libardi.

\section{Authors' contributions}

LZ developed the project, secured funding, collected the samples, performed experiments, analyzed data and wrote the manuscript. SP analyzed the data, prepared and edited figures and manuscript. TT analyzed the data, performed bio-statistical analyses, prepared figures and edited the manuscript. LC analyzed the data and edited the manuscript. GP performed digital droplet PCR analysis and analyzed the data. VS designed analysis strategies for ddPCR. VDS performed RNA sequencing analysis. RB performed RNA sequencing analysis. TL, MH and BD provided pediatric RNA samples B1,B2, B3 and B4. JP edited the manuscript. MP and RM provided pediatric RNA samples and edited the manuscript; CM: provided control samples and edited the manuscript. GB provided input in data analysis and edited the manuscript. PM led the project by supervising both bioinformatic and experimental studies and edited the manuscript. All authors read and approved the final manuscript.

\section{Funding}

This work was supported by the Fondazione Umberto Veronesi for 2017, 2018, 2019, and 2020 (LZ). This work was also supported by the AIL Trento Associazione Italiana contro le Leucemie-Linfomi e Mieloma O.D.V. and by the Associazione Albergatori ed Imprese Turistiche della Provincia di Trento (ASAT).

\section{Availability of data and materials}

All data generated or analysed during this study are included in this published article and its supplementary information files.

\section{Ethics approval and consent to participate}

Institutional review board approval was granted by the Comitato Etico per la Sperimentazione con l'Essere Umano (CESP) of the University of Trento (Prot. 2020-002).

\section{Consent for publication}

Not applicable.

\section{Competing interests}

The authors declare that they have no conflicts of interest.

\section{Author details}

${ }^{1}$ Laboratory of Molecular and Cellular Neurobiology, Department of CelIular, Computational and Integrative Biology - CIBIO, University of Trento, Trento, Italy. ${ }^{2}$ Bioinformatics Facility, Department of Cellular, Computational and Integrative Biology - CIBIO, University of Trento, Trento, Italy. ${ }^{3}$ Section of Hematology, Department of Internal Medicine and Yale Comprehensive Cancer Center, Yale University School of Medicine, New Haven, CT, USA.

${ }^{4}$ Centre for Genomic Regulation (CRG), Barcelona, Spain. ${ }^{5}$ High Throughput Screening (HTS) and Validation, CIBIO, University of Trento, Trento, Italy. ${ }^{6}$ Next Generation Sequencing Core Facility LaBSSAH - CIBIO, University of Trento, Trento, Italy. ${ }^{7}$ Department of Pediatric Hematology-Oncology and Stem Cell Transplantation, Ghent University Hospital, Ghent, Belgium. ${ }^{8}$ University Pompeu Fabra, Barcelona, Spain. ${ }^{9}$ Istituto Di Ricerca Pediatrica Città Della Speranza, Padua, Italy. ${ }^{10}$ Associazione italiana ematologia e oncologia pediatrica (AIEOP), Bologna, Italy. ${ }^{11}$ Centro di Ricerca EmatoOncologico (CREO), Perugia, Italy. ${ }^{12}$ Maternal and Child Health Department, Padua University, Padua, Italy. ${ }^{13}$ IIGM-Italian Institute for Genomic Medicine, Turin, Italy.

Received: 11 March 2020 Accepted: 5 October 2020

Published online: 12 October 2020

\section{References}

1. Rau AT, Shreedhara AK, Kumar S. Myelodysplastic syndromes in children: where are we today? Ochsner J. 2012;12:216-20.

2. Yu J, Li Y, Li T, Li Y, Xing H, Sun H, Sun L, Wan D, Liu Y, Xie X, Jiang Z. Gene mutational analysis by NGS and its clinical significance in patients with myelodysplastic syndrome and acute myeloid leukemia. Exp Hematol Oncol. 2020;6:9-2.

3. Schwartz JR, Ma J, Lamprecht T, Walsh M, Wang S, Bryant V, et al. The genomic landscape of pediatric myelodysplastic syndromes. Nature communications. 2017:8:1557.

4. Locatelli F, Zecca M, Pession A, Maserati E, De Stefano P, Severi F. Myelodysplastic syndromes: the pediatric point of view. Haematologica. 1995;80:268-79.

5. Bresolin S, Trentin L, Zecca M, Giordan M, Sainati L, Locatelli F, et al. Gene expression signatures of pediatric myelodysplastic syndromes are associated with risk of evolution into acute myeloid leukemia. Leukemia. 2012;26:1717-9.

6. Papaemmanuil E, Gerstung M, Malcovati L, Tauro S, Gundem G, Van Loo P, et al. Clinical and biological implications of driver mutations in myelodysplastic syndromes. Blood. 2013;122:3616-27.

7. Cazzola M, Della Porta MG, Malcovati L. The genetic basis of myelodysplasia and its clinical relevance. Blood. 2013;122:4021-34.

8. Hrustincova A, Krejcik Z, Kundrat D, Szikszai K, Belickova M, Pecherkova P, Klema J, Vesela J, Hruba M, Cermak J, Hrdinova T, Krijt M, Valka J, Jonasova A, Merkerova MD. Circulating small noncoding RNAs have specific expression patterns in plasma and extracellular vesicles in myelodysplastic syndromes and are predictive of patient outcome. Cells. 2020;9:E794. 
9. Yu J, Li Y, Zhang D, Wan D, Jiang Z. Clinical implications of recurrent gene mutations in acute myeloid leukemia. Exp Hematol Oncol. 2020;9:4.

10. Bejar R. Implications of molecular genetic diversity in myelodysplastic syndromes. Curr Opin Hematol. 2017;24:73-8.

\section{Publisher's Note}

Springer Nature remains neutral with regard to jurisdictional claims in published maps and institutional affiliations.
Ready to submit your research? Choose BMC and benefit from:

- fast, convenient online submission

- thorough peer review by experienced researchers in your field

- rapid publication on acceptance

- support for research data, including large and complex data types

- gold Open Access which fosters wider collaboration and increased citations

- maximum visibility for your research: over $100 \mathrm{M}$ website views per year

At BMC, research is always in progress.

Learn more biomedcentral.com/submissions 